\title{
Cursos de Jornalismo em perspectiva histórico- geográfica: arranjos locais e regionais no Brasil
}

Sonia Virgínia Moreira

Professora do Programa de Pós-Graduação em Comunicação (PPGCOM) da Universidade do Estado do Rio de Janeiro (UERJ).

E-mail: soniavm@gmail.com

Antonia Alves Pereira

Doutoranda em Comunicação pela UERJ e pela Universidade do Estado de Mato Grosso (Unemat). Mestre em Ciências da Comunicação pela Universidade de São Paulo. Professora do Curso de Jornalismo da Unemat.

E-mail: antoniaalves@unemat.br

Resumo: Este artigo analisa a expansão dos cursos de Jornalismo em instituições públicas e privadas de ensino superior e a distribuição geográfica das redes que se estabelecem entre os cursos em diferentes dimensões urbanas. Fundamenta-se em dados do Ministério da Educação e no conceito de hierarquia das cidades do IBGE para tratar das inserções regionais em espaços como metrópoles, cidades médias e cidades pequenas. Os dados coletados em pesquisa bibliográfica e nos bancos de dados indicam que políticas de ações afirmativas, como o financiamento estudantil e o sistema unificado de seleção e o ingresso de negros e pardos, indígenas e de pessoas com deficiência, influenciaram o fluxo de alunos entre cidades e regiões. Mostram, também, que o acesso ao ensino superior contribuiu para a diversidade e a inclusão social de jovens de baixa renda no processo de interiorização das universidades e dos cursos de jornalismo.

Palavras-chave: educação superior; cursos de jornalismo; regiões geográficas; escalas; Brasil.
Abstract: This paper analyzes the growth of journalism undergraduate courses in public and private universities and the geographic distribution of networks that are established among courses in many urban dimensions. It considers the regional insertions of the courses in different spaces, such as large, medium, and small cities according to the geographical concept of "hierarchy of the cities" formulated by the Brazilian Institute of Geography and Statistics, and on data gathered from the Brazilian Ministry of Education website. The data collected show that affirmative action policies, such as student financing, the unified selection system, and the entry of black and indigenous people and also persons with disabilities, increased the students' flow between cities and regions. They also reveal that access to higher education contributed to the diversity and social inclusion of youths with low-income in small cities reaching the universities and journalism undergraduate courses.

Keywords: higher education; journalism undergraduate courses; geographic regions; scales; Brazil. 


\section{comunicação \& educação • Ano XXVI • número 1 • jan/jun 2021}

\section{CONTEXTOS}

A cada ano, principalmente a partir da década de 1970, o espaço profissional do jornalismo (redações em meios convencionais do mercado ${ }^{1}$, comunitários ou independentes) recebe um número crescente de jornalistas formados em cursos distribuídos em várias regiões. Indicadores de 2019 do Atlas da Notícia, porém, mostram uma distribuição desigual de meios de comunicação nos 5.570 municípios brasileiros analisados: $62 \%$ são considerados "desertos" de notícias, sem qualquer veículo jornalístico (3.487 cidades); $19 \%$ são "quase desertos", com um ou dois veículos (1.074 cidades); e 19\% são "não-desertos", com três ou mais veículos (1.009 cidades) ${ }^{2}$. No período da coleta de dados do Atlas, foram fechados 331 veículos jornalísticos dentre os 13.732 mapeados.

A ausência de meios de comunicação em várias localidades indicou que seria possível estabelecer as seguintes conexões com o ensino de jornalismo: (1) Há no Brasil áreas que podem ser consideradas "desertos" de formação superior?; (2) Existem cursos de jornalismo em locais "desertos" ou "quase desertos" de notícias? A partir dessas questões, analisamos o processo histórico-geográfico de expansão dos cursos para chegar a um mapa possível de evolução do ensino de jornalismo. À abordagem geográfica foi agregada a abordagem educacional, com dados sobre os cursos e as políticas públicas para o ensino superior.

A regionalização e os conceitos de cidade elaborados pelo Instituto Brasileiro de Geografia e Estatística (IBGE) estão na base deste artigo: os cursos foram identificados por regiões de influência das cidades ${ }^{3}$ e regiões de articulação urbana ${ }^{4}$, de acordo com a distribuição territorial das universidades. O deslocamento dos estudantes é outro elemento-chave, pois alunos com maior

1. Impressos, on-line, rádio e televisão.

2. ATLAS DA NOTÍCIA. Os desertos de notícia no Brasil. Atlas da Notícia, Brasil, 2020. Disponível em: Disponível em: https://www.atlas jor.br/desertos-de-noticia/ Acesso em: 18 ago. 2020.

3. IBGE. Regiões de influência das cidades: 2018. Rio de Janeiro: IBGE, 2020.

4. IBGE. Divisão regional do Brasil em regiões geográficas imediatas e regiões geográficas intermediárias. Rio de Janeiro: IBGE, 2017.

5. MINISTÉRIO DAEDUCAÇÃO. e-MEC. Disponível em: http://emec.mec.gov. br. Acesso em: 18 jun. 2020.

6. IBGE. Divisão regional do Brasil em regiões geográficas imediatas e regiõ̃es geográficas intermediárias. Rio de Janeiro: IBGE, 2017. p. 9. pontuação no Exame Nacional do Ensino Médio (Enem) podem se matricular pelo Sistema Unificado de Seleção (Sisu) em instituições de estados diferentes da sua origem; e a seleção inclui políticas de interiorização e de expansão dos cursos superiores em instituições privadas, o financiamento estudantil (Fies) e o programa de bolsas Prouni. Na pesquisa de campo, o acesso aos dados da plataforma digital e-MEC, do Ministério da Educação ${ }^{5}$, mostrou inconsistências nos subsídios institucionais e exigiram dupla checagem nos websites das universidades para confirmar informações oficiais.

\section{ARTICULAÇÕES URBANO-REGIONAIS EM REDE}

A estrutura regional do Brasil tem sido explorada pelo IBGE desde a década de 1940, quando começaram a ser organizadas as camadas geográficas que estão na base dos conceitos de rede urbana. As identificações regionais evoluíram de Zonas Fisiográficas, em 1942 e 1960, para Microrregiões Homogêneas, em 1968; Mesorregiões homogêneas, em 1976; Microrregiões e Mesorregiões Geográficas, em 1990, até chegar às regiões de influência geográfica intermediárias e imediatas em 2017. 
[...] a definição de um novo quadro regional vinculada ao intenso processo de ocupação e ampliação dos espaços produtivos que, aliado ao acelerado movimento de criação de municípios, a partir da Constituição Federal do Brasil de 1988, coloca novos desafios metodológicos à sua construção. Nesse contexto, um duplo processo de mudança, não só estritamente socioeconômico, mas também de natureza político-administrativa, alterou a geografia do País, gerando diferenças e desigualdades que tornaram mais complexa a leitura de seu território, aumentando, assim, a demanda por uma nova Divisão Regional do Brasil no período que vai da última década do Século XX à primeira do Século XXI. ${ }^{6}$

As regiões de influência detalhadas no volume Regiões de Influência das Cidades: 2018 (Regic) $^{7}$ definem e delimitam a hierarquia dos centros urbanos nas várias regiões, bem como as redes que se estabelecem em escalas distintas entre os centros urbanos. Dependendo do seu grau de influência, as redes desenvolvem infraestruturas que abrigam atividades inovadoras de diferentes níveis e operam como centro de comando e controle: "O elo final de cada rede são as Metrópoles, para onde convergem as vinculações de todas as cidades presentes no Território Nacional" .

A metodologia do IBGE para a rede de influências urbanas identifica "[...] a atração exercida entre as Cidades próximas e as ligações de longa distância realizadas pela atuação de instituições públicas e privadas presentes nos centros urbanos" $"$. O recorte das unidades territoriais pela inclusão da mobilidade populacional "movida pelo trabalho e pelo estudo" e os vínculos com a formação em jornalismo também são centrais neste artigo.

Os critérios utilizados na identificação dos arranjos populacionais empregam a noção de integração, medida pelos movimentos pendulares para trabalho e estudo ou a contiguidade urbana, que assim sintetizam os vários processos envolvidos. [...] $\mathrm{Na}$ análise dos resultados, dois enfoques foram adotados: o primeiro refere-se aos arranjos populacionais propriamente ditos, tendo como finalidade apreender dinâmicas de mobilidade populacional; o segundo leva em conta o conceito de concentrações urbanas. Este último constitui um termo geral que supera, como escala de urbanização, as noções de arranjos populacionais e de municípios isolados: refere-se a unidades urbanas que impelem ao movimento um volume cada vez maior de pessoas, que veem, nos médios e grandes centros, oportunidades de trabalho e estudo, compatíveis com os novos padrões econômicos do capitalismo contemporâneo ${ }^{10}$.

Além das pesquisas do IBGE, consideramos os métodos desenvolvidos em estudos do Instituto de Pesquisa Econômica Aplicada (Ipea) para estruturas da rede urbana em regiões metropolitanas e em polos secundários de cidades médias, centradas na interiorização e na 'desconcentração' da região Sudeste, na ordenação do Sul, na dinamização econômica do Nordeste e na promoção da urbanização no Norte e no Centro-Oeste ${ }^{11}$.

\subsection{A expansão das universidades}

As primeiras universidades públicas surgiram a partir da década de 1920 e até o início dos anos 1960 reuniam a maioria dos 93 mil alunos matriculados no
7. IBGE. Regiões de influência das cidades: 2018. Rio de Janeiro: IBGE, 2020.

8. Ibidem. p. 13.

9. Ibidem. p. 74.

10. IBGE. Arranjos populacionais e concentrações urbanas no Brasil. Rio de Janeiro: IBGE, 2015. p. 19.

11. MOTTA, Diana M. In: PEREIRA, Rafael Henrique Moraes; FURTADO, Bernardo Alves (org.). Dinâmica urbano-regional: rede urbana e suas interfaces. Brasília: IPEA, 2011. p. 13-14. 
12. NEVES, Clarissa Eckert Baeta; MARTINS, Carlos Benedito. Ensino superior no Brasil: uma visão abrangente. In: DWYER, Tom et al. (org.). Jovens universitários em um mundo em transformação: uma pesquisa sino-brasileira. Brasília: Ipea, 2016. p. 97

13. SALATA, André. Ensino superior no Brasil das últimas décadas: redução nas desigualdades de acesso?. Tempo Social, São Paulo, v. 30, n. 2, p. $226,2018$.

14. A Lei $n^{\circ} 3.708 / 2001$, no Rio de Janeiro, foi pioneira na instituição de cotas.

15. CAJAZEIRA, Paulo Eduardo Silva Lins. As perspectivas de atuação do egresso de Jornalismo do Reuni no Ceará em telejornais locais. In: CONGRESSO BRASILEIRO DE CIÊNCIASDA COMUNICAÇÃO, 41., 2018, Joinville. Anais [...]. Joinville: Intercom, 2018. p. 3.

16. MINISTÉRIO DA EDUCAÇÃO. Expansão. 2010. Disponível em: http://reuni.mec.gov.br/expansao. Acesso em: 8 ago. 2020.

17. ALMEIDA FILHO, Naomar. Educação superior em Lula x FHC: a prova dos números. Carta Maior, Brasil, 2010. Disponivel em: https://www.cartamaior.com. br/?/Editoria/Educacao/ Educacao-superior-em-Lula-x-FHC-a-prova-dos-numeros/13/16291. Acesso em: 16 jun. 2020.

18. NEVES, Clarissa Eckert Baeta; MARTINS, Carlos Benedito. op. cit., 2016. p. 108.

19. Ibidem. p. 108.

20. Ibidem. p. 112

21. PAIM, Antonio. A UDF e a ideia de Universidade. Rio de Janeiro: Tempo Brasileiro, 1981. p. 76. ensino superior. Começando em 1965, a política desenvolvimentista do regime militar (1964-1985) construiu a rede de universidades federais em todos os estados e o sistema educacional chegou a 352 mil estudantes ${ }^{12}$. A partir de 2000, as universidades se caracterizam pela democratização do ensino nas públicas e pela forte participação do setor privado $^{13}$ na educação. Nas instituições federais, estaduais e municipais, as políticas afirmativas e o Sistema de Seleção Unificada (Sisu) facilitam a movimentação dos estudantes entre estados e regiões. A partir de 2001, leis estaduais ${ }^{14}$ e resoluções institucionais introduzem o sistema de reserva de vagas para negros, pardos e indígenas nas universidades, normatizado em 2012 pela Lei de Cotas ( $\left.n^{\circ} 12.711\right)$.

A inclusão de jovens de baixa renda cresce com o uso de créditos como o Fundo de Financiamento Estudantil (Fies), de 1999, que financia em até 50\% os cursos de graduação, e o Programa Universidade para Todos (Prouni), de 2004, que concede bolsas de estudo integrais ou parciais (50\% e $25 \%$ ) em cursos superiores com base na nota obtida no Exame Nacional do Ensino Médio (Enem). Além do crédito estudantil, o financiamento das instituições privadas vem das mensalidades pagas e de fontes como isenções fiscais e previdenciárias.

O Programa de Apoio a Planos de Reestruturação e Expansão das Universidades Federais (Reuni) pretendeu ampliar o acesso dos estudantes, ao constatar que apenas 24,3\% dos jovens brasileiros entre 18 e 24 anos conseguiam chegar ao ensino superior ${ }^{15}$. Implantado em 2007 com metas para cinco anos e 53 universidades participantes, o Reuni se destinou a ampliar os cursos de graduação e de pós-graduação; melhorar o índice de conclusão na graduação para $90 \%$; manter a relação de 18 alunos por professor; e expandir em pelo menos $20 \%$ as matrículas na graduação. Para atingir o objetivo, foram criadas 14 universidades federais e 100 campi, que no final de 2011 chegaram a $237^{16}$. As políticas inclusivas aumentaram o volume de matrículas em $90 \%$, com taxa média de crescimento de $11 \%$ entre 2003 e $2010^{17}$.

A expansão resultou tanto do planejamento oficial ${ }^{18}$ como para atender a lógica da demanda e da oferta pelo ensino superior. Entre 1995 e 2012, a multiplicação de entradas em cursos presenciais e à distância chegou a $360 \%$, subindo de 1,7 para 7 milhões de estudantes ${ }^{19}$, o que contribuiu para a diversidade e a inclusão social de jovens de baixa renda nas universidades ${ }^{20}$. $\mathrm{O}$ mapeamento dos cursos de jornalismo nas regiões de influência e de articulação urbana confirma esses dados.

\subsection{Os cursos nas universidades}

Os cursos de jornalismo surgiram em momentos de intensa mobilização de governos, em especial com Vargas na presidência (1930-1945 e 1951-1954). Em 1937, o educador Anísio Teixeira inspirou a criação da Universidade do Distrito Federal (UDF) e, nela, o curso considerado pioneiro ${ }^{21}$. A experiência foi breve, com a UDF fechada pelo Estado Novo de Vargas em dezembro de 1938. 
No segundo período Vargas, seguindo a política econômica nacionalista do projeto de modernização do país, três cursos seriam criados em instituições federais e dois em confessionais nos Estados de Minas Gerais, Bahia, Rio de Janeiro e Rio Grande do Sul.

A partir dos anos 1950, a incorporação do modelo empresarial de qualificação editorial inspirada no estilo de jornalismo importado dos Estados Unidos, "[...] que fornece a técnica do lead e os manuais de redação"22, e os investimentos em equipamentos modernos provocam uma revolução gráfica nos jornais e mudanças do marketing das empresas e nas técnicas da notícia. Nos anos 1960, os Cadernos de Jornalismo e Comunicação são criados pelo jornalista Alberto Dines, no Jornal do Brasil, no Rio de Janeiro, para "[...] estimular o processo de aprimoramento técnico dos jornalistas". Os Cadernos, precursores do conteúdo crítico dos cursos de jornalismo, circularam em 49 edições, a partir de $1965^{23}$.

Na década de 1980 foram fundados 26 cursos: oito em instituições federais, dois em estaduais, um em instituição municipal, seis em confessionais e dez em instituições privadas, distribuídos pelas regiões Sudeste (17), Nordeste (quatro), Centro-Oeste (um), Sul (três) e Norte (um). Os cursos de jornalismo triplicam na década de 1990 com a criação de 67 cursos, sendo 25 em capitais estaduais.

O terreno fértil da tecnologia e da inovação e as iniciativas de inserção dos jovens nas universidades resultaram na criação de 223 cursos no início do milênio. Na primeira década de 2000, foram inaugurados cursos de jornalismo em 70 espaços urbanos de maior porte (metrópoles, capitais estaduais ou cidades grandes); em cidades médias (62) e em cidades pequenas (16). Desses cursos, 13 estavam em instituições federais, quatro em estaduais, um em instituição municipal e sete em instituições confessionais. Nas universidades privadas, os cursos se distribuíram por todas as regiões: Sudeste (27), Nordeste (20), Centro-Oeste (nove), Norte (sete) e Sul (três).

\subsection{Os cursos nas regiões}

Os cursos de Jornalismo em universidades públicas, privadas e comunitárias são credenciados de acordo com o Art. 19 da Lei de Diretrizes e Bases da Educação (Lei $\mathrm{n}^{\circ}$ 9.394/1996). Nos 415 registros encontrados no sistema e-MEC ${ }^{24}$, filtros com as palavras-chave "curso de Jornalismo", "ensino presencial" e "em atividade" eliminaram registros em duplicidade (24), cursos extintos (47) e não iniciados (37). Com isso, identificamos 354 cursos de jornalismo em 315 instituições localizadas nas regiões Sudeste (166), Sul (68), Nordeste (64), Centro-Oeste (30) e Norte (26). Os cursos estão principalmente em instituições privadas (253) e o restante se distribui entre universidades federais (45), confessionais (30), estaduais (16) e municipais (10), como mostram os dados da Tabela 1.
22. BAHIA, Juarez. Jornal, história e técnica. São Paulo: Ática, 1990. p. 382-383.

23. JAWSNICKER, Cláudia. Cadernos de jornalismo e comunicação: iniciativa precursora de media criticism no Brasil. Alceu, Rio de Janeiro, v. 8, n. 16, p. 150158, 2008. Disponível em: http://revistaalceu-acervo. com.puc-rio.br/media/alceu_n16_Jawsnicker.pdf. Acesso em: 10 jun. 2020.

24. MINISTÉRIO DA EDUCAÇÃO. Cadastro Nacional de Cursos e Instituições de Educação Superior. Disponível em: http:// emec.mec.gov.br. Acesso em: 10 jun. 2020. 
comunicação \& educação • Ano XXVI • número 1 • jan/jun 2021

Tabela 1: Cursos de Jornalismo por região e tipo de instituição

\begin{tabular}{c|c|c|c|c|c|c}
\multirow{2}{*}{ Regiões } & \multicolumn{7}{c}{ Tipos de Instituição } \\
\cline { 2 - 7 } Sudeste & 11 & 6 & 5 & 16 & 128 & 166 \\
\hline Sul & 8 & 3 & 4 & 9 & 44 & 68 \\
\hline Nordeste & 12 & 6 & 0 & 2 & 44 & 64 \\
\hline Centro-Oeste & 5 & 1 & 0 & 3 & 21 & 30 \\
\hline Norte & 9 & 0 & 1 & 0 & 16 & 26 \\
\hline & $\mathbf{4 5}$ & 16 & 10 & 30 & $\mathbf{2 5 3}$ & $\mathbf{3 5 4}$ \\
\hline
\end{tabular}

Fonte: Elaboração das autoras com dados do sistema e-MEC (Ministério da Educação), 2019.

Há evidências de que muitos cursos de jornalismo surgiram em resposta à demanda de mercados locais, motivados por políticas de expansão do ensino superior ou incentivados por períodos de estabilidade econômica (Gráfico 1). Atualmente os cursos se distribuem nacionalmente, mas com evidente desequilíbrio entre universidades públicas (71) e privadas/confessionais (283), que predominam em especial na região Sudeste. Há paridade numérica de cursos em instituições privadas do Nordeste (44) e do Sul (44), enquanto as 30 instituições confessionais se concentram no Sudeste e no $\mathrm{Sul}^{25}$.

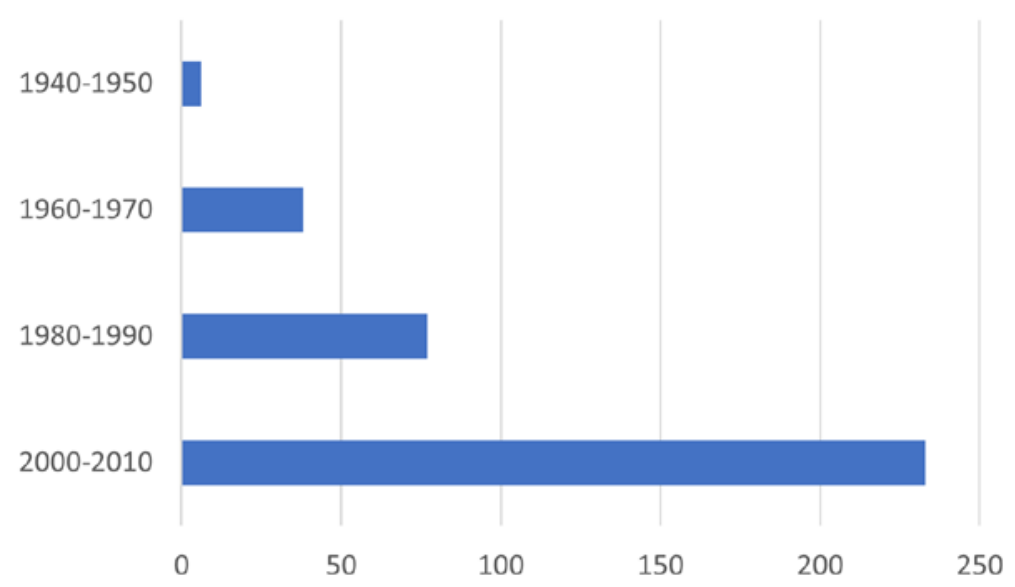

Gráfico 1: Cursos de Jornalismo criados entre 1940 e 2010

Fonte: Elaboração das autoras com dados do sistema e-MEC (Ministério da Educação), 2020.

25. No Centro-Oeste, três confessionais oferecem cursos de jornalismo; e, no Nordeste, duas (em Recife e em Salvador, apesar de o de Salvador ainda não constar da plataforma e-MEC).

Em termos gerais, a maioria dos cursos da região Sudeste é mantida por instituições privadas (128) nos estados de São Paulo (83), Rio de Janeiro (30), Minas Gerais (27) e Espírito Santo (quatro). Em relação às públicas, apenas no estado de São Paulo não há instituição federal com curso de jornalismo. No Nordeste, os cursos estão principalmente nas federais (12) e estaduais (seis), enquanto na região Sul há equilíbrio entre as instituições federais (oito) e confessionais (nove), e entre as estaduais (três) e municipais (quatro). 


\subsection{Os cursos nas cidades}

Das 88 cidades com curso de jornalismo, 64 são sedes das regiões de articulação urbana imediata (algumas estão também em regiões intermediárias). Os dados coletados mostram forte presença dos cursos de jornalismo nas regiões intermediárias, em que 24 cidades estão próximas a uma região imediata - 20 no Sudeste, duas no Sul, uma no Norte e uma no Nordeste $^{26}$. Os cursos se concentram principalmente em cidades médias das Regiões Sudeste, Sul, Nordeste, Norte e Centro-Oeste, nessa ordem. Em relação ao alcance das redes de influência ${ }^{27}$, os cursos se distribuem entre metrópoles, grandes cidades, cidades médias e pequenas. O ensino de jornalismo está presente nas metrópoles (142 cursos), nas cidades médias (129 cursos), em cidades grandes (46 cursos) e em cidades de médio, longo e curto alcance (95 cursos no total). Conforme dados do MEC até 2019 é possível visualizar que os cursos estão concentrados nos estados litorâneos e no interior dos estados das regiões Sudeste e Sul, principalmente São Paulo (Figura 1).

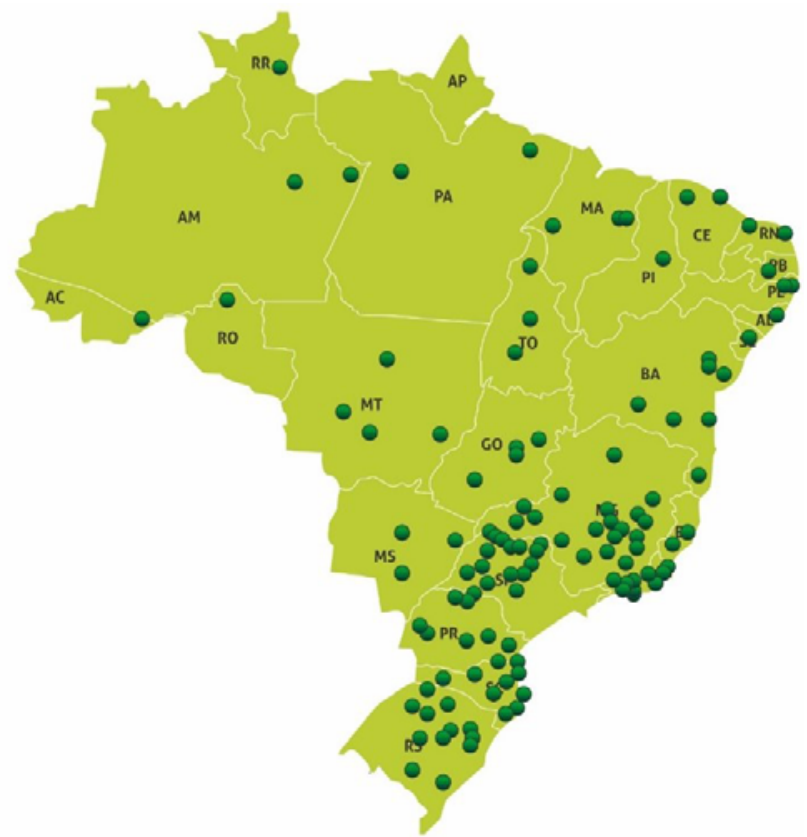

Figura 1: Cidades brasileiras com cursos de jornalismo, 2019 Fonte: Elaboração das autoras com dados do sistema e-MEC (Ministério da Educação).

O exame dos dados referenciados pela hierarquia das cidades e suas áreas de influência permite responder as duas questões deste artigo: (1) Há no Brasil áreas que podem ser consideradas "desertos" em formação superior?; (2) Existem cursos de jornalismo em locais "desertos" ou "quase desertos" de notícias ou o ensino está circunscrito aos grandes centros e cidades médias?

Os "desertos" ou "quase desertos" do Atlas da Notícia 2019 estão localizados em cidades com população média de 7 mil habitantes. Levando em conta a
26. Cachoeira-BA-Cruz das Almas/imediata; Ananindeua-Belém/imediata; Navegantes - Itajaí/imediata; Frederico Westphalen-RS e Lajeado - Santa Cruz do Sul/imediata; Bebedouro - Barretos/imediata; Cachoeira Paulista-Cruzeiro/ imediata; Caratinga - Ipatinga, imediata; Lorena Guaratinguetá/imediata; Engenheiro Coelho - Limeira/imediata; Campo Limpo Paulista - Jundiaí/ imediata; Guarulhos, Mogi das Cruzes, São Bernardo do Campo, Osasco e São Caetano do Sul-São Paulo/ imediata; Duque de Caxias, Niterói, São Gonçalo e Seropédica - Rio de Janeiro/ imediata; Ouro Preto-Santa Bárbara/imediata; Salto, Avaré e Itu-Sorocaba/imediata; e Vila Velha - Vitória/ imediata.

27. SCHERER, Clauber Eduardo Marchezan; AMARAL, Pedro Vasconcelos Maia. O espaço e o lugar das cidades médias na rede urbana brasileira. Revista Brasileira de Estudos Urbanos e Regionais, Rio de Janeiro, v. 22, p. 13, 2020. 
28. SILVA, Andresa Lourenço. Breve discussão sobre o conceito de cidade média. Geoingá, Londrina, v. 5, n. 1, p. 58-76, 2013. p. 42.

29. SPOSITO, Maria Encarnação Beltrão. O desafio metodológico da abordagem interescalar no estudo de cidades médias no mundo contemporâneo. Cidades, Rio Claro, v. 3, n. 5, p. 143-157, 2006. p. 151.

30. SCHERER, Clauber Eduardo Marchezan.; AMARAL, Pedro Vasconcelos Maia. op. cit., 2020. p. 4

31. Ibidem. p. 13.

32. SILVA, Andresa Lourenço. op. cit., 2013.

33. LEITZKE, Airton; FRESCA, Tânia Maria. op. cit., 2009. p. 7.

34. CASTELLO BRANCO, Maria Luisa. op. cit., 2006. p. 68.

35. AMORIM FILHO, Oswaldo Bueno.: RIGOTTI, José Irineu Rangel. Os limiares demográficos na caracterização das cidades médias. In: ENCCONTRO DA ASSOCIAÇÃO BRASILEIRA DEESTUDOSPOPULACIONAIS, 13., 2002, Ouro Preto. Anais [...]. Ouro Preto: Abep, 2002. p. 9.

36. SANTOS, Milton; SILVEIRA, Maria Laura. O Brasil: território e sociedade no início do século XXI. Rio de Janeiro: Record, 2001. p. 280. estimativa populacional do IBGE para 2019, nenhuma das cidades com cursos de Jornalismo se enquadraria nessa definição, pois a menor camada demográfica considerada está na faixa superior a 20 mil habitantes. A partir da hierarquia das cidades e suas regiões de influência, ordenadas por articulações geográficas imediatas e intermediárias, constatamos que os cursos se localizam principalmente em cidades médias (entre 100 e 500 mil habitantes) ou metrópoles (acima de um milhão de habitantes). Uma parcela reduzida foi encontrada em cidades pequenas (entre 50 e 100 mil habitantes).

É importante registrar que não existe consenso sobre o conceito de cidades médias. Em dados demográficos, o IBGE considera cidades médias aquelas com população entre 100 e 500 mil habitantes, enquanto a Organização das Nações Unidas classifica na mesma categoria cidades com entre $100 \mathrm{mil} \mathrm{e} \mathrm{um}$ milhão de habitantes ${ }^{28}$. Outros fatores interferem na classificação, entre eles o papel desempenhado pelas cidades enquanto redes urbanas de intermediação regional. Nesta concepção, as cidades médias deixam de ser avaliadas apenas pelo seu espaço de influência, pois os sistemas de geolocalização e informatização ampliaram sua escala e abrangência ${ }^{29}$.

Scherer e Amaral ${ }^{30}$ analisaram os censos de 2000 e de 2010 para identificar posições intermediárias nas redes formadas pelas cidades médias, considerando que uma cidade com 100 mil habitantes em São Paulo tem inserção distinta de outra com a mesma dimensão em Roraima. Assim, seriam três as categorias definidoras de cidades médias:

[...] Cidades médias de longo alcance, grupo caracterizado por centros com economias dinâmicas e que possuem inserção bastante sólida no contexto regional. As cidades médias de médio alcance abrigam os centros que, apesar de ainda não terem sido capazes de se inserir no cenário regional de maneira ampla, têm uma inserção que não se limita ao atendimento de uma demanda local, constituindo-se, assim, em atores de intermediação regional. Por fim, têm-se as cidades médias de curto alcance, as quais se apresentam como cidades que, apesar de em nível macrorregional terem uma condição de inserção local, exercem influência sobre a vizinhança imediata ${ }^{31}$.

Ainda sobre o conceito de cidade média, $\mathrm{Silva}^{32}$ as identifica como regionais e extrarregionais, com fluxos materiais e imateriais estabelecidos em todos os setores $^{33}$, inclusive seu grau de urbanização, qualidade de vida e centralidade ${ }^{34}$. A diversificação na organização espacial das cidades médias decorre de interações constantes e duradoras nesse que é um centro de crescimento econômico e regional com capacidade de receber migrantes de cidades menores ${ }^{35}$. Sob esse aspecto, as cidades médias apresentam serviços de consumo familiar, administrativo e empresarial, operando como fóruns regionais ${ }^{36}$, organizadas em torno de uma elite empreendedora capaz de competir com metrópoles e grandes cidades em redes de interações espaciais complexas, multidirecionais e em múltiplas escalas (regional, nacional e internacional) ${ }^{37}$. 


\section{CONSIDERAÇÕES FINAIS}

O crescimento dos cursos de jornalismo no Brasil, como vemos, está historicamente associado a políticas de expansão do ensino superior, especialmente o programa Reuni, e a políticas públicas voltadas para o ingresso de estudantes de baixa renda no ensino superior, subsidiados por financiamentos como o Fies e Prouni. Os cursos de jornalismo registrados no Ministério da Educação concentram-se em 150 dos 5.570 municípios brasileiros. Seu principal desafio está na formação de jornalistas que precisam atender (e entender) a demanda da sociedade por um profissional com capacidade de apurar e oferecer informações e, assim, contribuir para evitar a ocorrência dos "desertos de notícias".

Apesar das dificuldades encontradas nos meses de pesquisa em banco de dados, foi possível mapear aqui os cursos de jornalismo situados nas metrópoles, nas cidades médias e em cidades pequenas. Os resultados mostram que a maioria dos cursos se localiza em cidades médias, seguidas dos grandes centros $^{38}$. Sua expansão foi mais intensa entre as décadas 1990 e 2010, mas os anos 1970 mostram crescimento razoável para a época, com o estabelecimento de 27 cursos em todo o território nacional. Condições históricas, geográficas e culturais contribuíram para a conjuntura em que os cursos foram criados, como se depreende da análise das políticas de governo para o ensino superior ao longo de várias décadas.

Dois desafios se apresentam agora para o ensino superior brasileiro: o primeiro e mais importante é manter a qualidade na graduação, mesmo com a redução dos recursos nas universidades públicas e, especialmente, nas instituições privadas, que tinham 6,4 milhões de alunos matriculados em 2018, equivalente a $75 \%$ dos estudantes em cursos superiores. Ou seja: de cada quatro estudantes de graduação, três estavam em instituição particular. Em 2019, o Fundo de Financiamento Estudantil (Fies) deixou de ser a principal porta de entrada dos estudantes ao ensino superior: "Do total de 732,6 mil contratos firmados em 2014 (antes da recessão e de um primeiro reordenamento) o programa encerrou 2019 com apenas 84,9 mil contratos" (MORAES, 2020), com o valor da dívida dos alunos das universidades privadas chegando a R \$ 15,9 bilhões em 2019 (AMADO, 2020).

O segundo desafio está relacionado principalmente às instituições federais e diz respeito à evasão, ainda que em relação aos cursos de jornalismo seja fundamental assinalar que, em 2018, estavam na faixa de evasão zero, como mostrou o Censo da Educação Superior do Instituto Nacional de Estudos e Pesquisas Educacionais Anísio Teixeira ${ }^{39}$. É fato, porém, que o número de estudantes que abandonam os cursos pode crescer, tanto por razões econômicas (a necessidade de conciliar trabalho e estudo) como por dificuldade de acesso físico, porque no extenso território brasileiro muitos ainda precisam se deslocar por vários quilômetros para poder chegar às cidades nas quais estão os cursos. Dessa forma, os fluxos de circulação entre cidades são, mais que uma referência para políticas educacionais contemporâneas, instrumentos que podem contribuir para superar essa limitação enfrentada pelos estudantes, inclusive os alunos de cursos de Jornalismo.
37. CORRÊA, Roberto Lobato. Construindo o conceito de cidade média. In: SPOSITO, Maria Encarnação Beltrão. Cidades médias: espaços em transição. Expressão Popular: São Paulo, 2007. p. 29.

38. INEP. Censo da educação superior. Brasília: MEC, 2019. p. 11.

39. INEP. Censo da educação superior. Brasília, DF: MEC, 2019. Disponível em: http://download.inep. gov.br/educacao_superior/ censo_superior/documentos/2019/apresentacao censo_superior2018.pdf. Acesso em: 31 jul. 2020. 


\section{REFERÊNCIAS BIBLIOGRÁFICAS}

ALMEIDA FILHO, Naomar. Educação superior em Lula x FHC: a prova dos números. Carta Maior, Brasil, 2010. Disponível em: https://www.cartamaior. com.br/?/Editoria/Educacao/Educacao-superior-em-Lula-x-FHC-a-provados-numeros/13/16291. Acesso em: 8 jan. 2020.

AMADO, Guilherme. Estudantes devem R\$ 15,9 bilhões ao Fies; veja universidades campeãs. Época, Rio de Janeiro, 22 out. 2019. Disponível em: https:/ / epoca.globo.com/guilherme-amado/estudantes-devem-159-bilhoesao-fies-veja-universidades-campeas-24033049. Acesso em: 21 jun. 2021.

AMORIM FILHO, Oswaldo Bueno.; RIGOTTI, José Irineu Rangel. Os limiares demográficos na caracterização das cidades médias. In: ENCONTRO DA ASSOCIAÇÃO BRASILEIRA DE ESTUDOS POPULACIONAIS, 13., 2002, Ouro Preto. Anais [...]. Ouro Preto: Abep, 2002. p. 9.

ATLAS DA NOTÍCIA. Os desertos de notícia no Brasil. Atlas da Notícia, Brasil, 2020. Disponível em: Disponível em: https://www.atlas.jor.br/desertos-denoticia/. Acesso em: 2 maio 2020.

BAHIA, Juarez. Jornal, história e técnica. São Paulo: Ática, 1990.

CAJAZEIRA, Paulo Eduardo Silva Lins. As perspectivas de atuação do egresso de Jornalismo do Reuni no Ceará em telejornais locais. In: CONGRESSO BRASILEIRO DE CIÊNCIAS DA COMUNICAÇÃO, 41., 2018, Joinville. Anais [...]. Joinville: Intercom, 2018.

CASTELLO BRANCO, Maria Luisa. Cidades médias no Brasil. In: SPOSITO, Eliseu Savério; SPOSITO, Maria Encarnação Beltrão; SOBARZO, Oscar (org.). Cidades médias: produção do espaço urbano e regional. São Paulo: Expressão Popular, 2006. p. 245-277.

CORRÊA, Roberto Lobato. Construindo o conceito de cidade média. In: SPOSITO, Maria Encarnação Beltrão. Cidades médias: espaços em transição. Expressão Popular: São Paulo, 2007.

IBGE. Regiões de influência das cidades. Rio de Janeiro: IBGE, 2020.

IBGE. Conheça cidades e estados do Brasil. Rio de Janeiro: IBGE, 2019. Disponível em: https:/ / cidades.ibge.gov.br/. Acesso em: 29 ago. 2020.

IBGE. Divisão regional do Brasil em regiões geográficas imediatas e regiões geográficas intermediárias. Rio de Janeiro: IBGE, 2017.

IBGE. Arranjos populacionais e concentrações urbanas no Brasil. Rio de Janeiro: IBGE, 2015. 
INEP. Censo da educação superior. Brasília, DF: MEC, 2019. Disponível em: http:/ / download.inep.gov.br/educacao_superior/censo_superior/documentos/2019/ apresentacao_censo_superior2018.pdf. Acesso em: 31 jul. 2020.

JAWSNICKER, Cláudia. Cadernos de jornalismo e comunicação: iniciativa precursora de media criticism no Brasil. Alceu, Rio de Janeiro, v. 8, n. 16, p. 150-158, 2008.

LEITZKE, Airton; FRESCA, Tânia Maria. Londrina não é cidade média. In: SEMANA DE GEOGRAFIA, 25., 2009, Londrina. Anais [...]. Londrina: UEL, 2009.

MINISTÉRIO DA EDUCAÇÃO. e-MEC. Disponível em: http://emec.mec. gov.br. Acesso em: 18 jun. 2020.

MINISTÉRIO DA EDUCAÇÃO. Cadastro Nacional de Cursos e Instituições de Educação Superior. Disponível em: http:/ / emec.mec.gov.br. Acesso em: 10 jun. 2020

MINISTÉRIO DA EDUCAÇÃO. Expansão. 2010. Disponível em: http:// reuni.mec.gov.br/expansao. Acesso em: 8 ago. 2020

MORAES, Lucas. Fies acumula redução de contratos e empurra estudantes para financiamento privado. JC Pernambuco, Recife, 27 jan. 2020. Disponível em: https://jc.ne10.uol.com.br/canal/economia/nacional/noticia/2020/01/27/ fies-acumula-reducao-de-contratos-e-empurra-estudantes-para-financiamentoprivado-398131.php. Acesso em: 2 ago. 2020.

MOTTA, Diana M. Prefácio. In:PEREIRA, Rafael Henrique Moraes; FURTADO, Bernardo Alves (org.). Dinâmica urbano-regional: rede urbana e suas interfaces. Brasília: IPEA, 2011.

NEVES, Clarissa Eckert Baeta; MARTINS, Carlos Benedito. Ensino superior no Brasil: uma visão abrangente. In: DWYER, Tom et al. (org.). Jovens universitários em um mundo em transformação: uma pesquisa sino-brasileira. Brasília, DF: IPEA, 2016.

PAIM, Antonio. A UDF e a ideia de Universidade. Rio de Janeiro: Tempo Brasileiro, 1981.

SALATA, André. Ensino superior no Brasil das últimas décadas: redução nas desigualdades de acesso?. Tempo Social, São Paulo, v. 30, n. 2, p. 219-253, 2018.

SANTOS, Milton; SILVEIRA, Maria Laura. O Brasil: território e sociedade no início do século XXI. Rio de Janeiro: Record, 2001.

SCHERER, Clauber Eduardo Marchezan.; AMARAL, Pedro Vasconcelos Maia O espaço e o lugar das cidades médias na rede urbana brasileira. Revista Brasileira de Estudos Urbanos e Regionais, Rio de Janeiro, v. 22, 2020. 
comunicação \& educação • Ano XXVI • número 1 • jan/jun 2021

SILVA, Andresa Lourenço. Breve discussão sobre o conceito de cidade média. Geoingá, Londrina, v. 5, n. 1, p. 58-76, 2013.

SPOSITO, Maria Encarnação Beltrão. O desafio metodológico da abordagem interescalar no estudo de cidades médias no mundo contemporâneo. Cidades, Rio Claro, v. 3, n. 5, p. 143-157, 2006. 